\title{
GPPS-BJ-2019-0198
}

\section{A COMPARISON OF STEADY-STATE MODELS FOR PRESSURE GAIN COMBUSTION IN GAS TURBINE PERFORMANCE SIMULATION}

\author{
Nicolai Neumann \\ Chair for Aero Engines \\ Institute of Aeronautics and Astronautics \\ Technische Universität Berlin \\ Nicolai.Neumann@ilr.tu-berlin.de \\ Berlin Germany
}

\author{
Dominik Woelki \\ Chair for Aero Engines \\ Institute of Aeronautics and Astronautics \\ Technische Universität Berlin \\ Dominik.Woelki@ilr.tu-berlin.de \\ Berlin Germany
}

\author{
Dieter Peitsch \\ Chair for Aero Engines \\ Institute of Aeronautics and Astronautics \\ Technische Universität Berlin \\ Dieter.Peitsch@ilr.tu-berlin.de \\ Berlin Germany
}

\begin{abstract}
Pressure gain combustion (PGC) is widely considered to improve gas turbine thermal efficiency substantially. However, there is no consensus on the modelling in gas turbine performance simulation. Even though it remains the main tool for design studies, the steady-state 0D representation has difficulties in modelling the inherently intermittent behaviour of pressure gain combustion. Selecting the optimal gas turbine design is therefore difficult as common PGC models tend to under- or overestimate performance. In this paper, an algebraic combustor model is inferred from published CFD data and varied to have an optimistic and pessimistic representation. These models among others will be used in an optimisation to identify the best gas turbine design with respect to thermal efficiency. The consideration of the secondary air system and blade metal temperatures ensure a realistic case study. At the end of this paper, sensitivity studies shed light on cycle design at uncertain combustor performance. The selected PGC models achieve an improvement in thermal efficiency between $3.8-6.6$ percentage points compared to conventional isobaric combustion. However, this is less than half the 13.3 percentage points gain promised by ideal isochoric combustion.
\end{abstract}

\section{INTRODUCTION}

Pressure gain combustion is a technology that has the potential to substantially improve thermal efficiency for gas turbines. The benefit of isochoric combustion is associated with the reduced production of entropy during the combustion process compared to conventional constant pressure combustion. Though, this comes with a substantial drawback, namely an intermittent process which increases complexity. This is not only true for associated physics of PGC but also for modelling PGC in conventional steady-state gas turbine performance simulations. The principal question is what representative pressure at the combustor outlet should be used to describe this inherently unsteady process. Without a profound estimate no accurate cycle design is possible.

In the past a gas turbine with PGC is approximated by the Humphrey cycle, the Zeldovich, von Neumann, Döring (ZND) cycle (Heiser \& Pratt, 2002) and the Fickett-Jacobs (FJ) cycle (Vutthivithayarak, et al., 2012). Apart from assuming isentropic component behaviour, the assumption of idealistic isochoric (Humphrey) or detonative combustion given by the Chapman-Jouguet condition (ZND and FJ) overestimates overall performance. This is because neither model correctly captures the non-uniformity of the exhaust flow (Paxson, 2010) (Paxson \& Kaemming, 2014). According to the same authors, PGC converts the usual Brayton / Joule cycle to something approaching an Atkinson cycle. Therefore, constant volume combustion is just the ideal case realisations such as pulsed detonation combustion or shockless explosion combustion aim to achieve. More realistic models of PGC were presented by (Nalim, 2002), (Endo, et al., 2004), (Paxson, 2004), (Goldmeer, et al., 2008). All of them are suitable for steady-state OD gas turbine performance simulation. Therein, it is already assumed that the total kinetic energy at combustor exit during exhaust phase is not 
thoroughly available for work transfer in the turbine (Kaemming \& Paxson, 2018). However, the models' performances deviate from each other. Furthermore, these models were investigated in a gas turbine engine from a thermodynamic perspective such as in (Snyder \& Nalim, 2012). Studies on the integration into a gas turbine using realistic side conditions have been performed by (Grönstedt, et al., 2014), (Xisto, et al., 2017), (Sousa, et al., 2017) and (Stathopoulos, 2018). Still, complete gas turbine optimisations regarding thermal efficiency for various combustor models and their comparison using realistic constraints are not yet available.

For this paper, different models for the representation of a PGC were implemented into the gas turbine performance code GTlab-Performance (Becker, et al., 2011). On the one hand, models from the literature ((Goldmeer, et al., 2008) (Nalim, 2002) (Paxson, 1992)) are implemented, on the other hand a model named Mix was created, which matches published CFD data of (Paxson, 2010). For this created model an optimistic and pessimistic version were included. For each model a cycle optimisation study was conducted using the representation of a real gas turbine. This includes modelling of the secondary air system (SAS), the additional compressor in the SAS, blade temperature model for the first nozzle guide vane $(\mathrm{NGV})$ and effects of cooling air mass flow on turbine efficiency. The optimisation identifies optima with respect to thermal efficiency at constant NGV metal temperature and power output. The optimised cycle designs will be compared to each other and sensitivity studies will be presented at the point of optimal configuration.

This paper contributes a new PGC model which is fitted to CFD data. Uncertainties of PGC and their effect on cycle design of a real gas turbine are addressed. Optimisation results shed some light on possible gas turbine designs.

\section{PRESSURE GAIN COMBUSTOR MODEL}

For this study, only pressure gain combustor models are presented which support an implementation in 0D gas turbine performance simulations. In general, the combustor outlet temperature is defined by the energy balance around the combustor. The main challenge for steady state performance simulations is to infer the combustor pressure ratio (Paxson, 2010) which, according to the theory, lies in between a purely isobaric and ideal isochoric change of state.

\section{Published models}

Models provided by Paxson (Paxson, 1992) and Goldmeer (Goldmeer, et al., 2008) calculate the pressure ratio (PR) from an enthalpy ratio (HR) which is given by the fuel flow. The model is repeated here. First, a non-dimensional heat is calculated giving the enthalpy ratio from an energy balance around the combustor (eq. 1 and 2). The pressure ratio is then derived in eq. 3 using a tuning factor, which is 0.12 according to Paxson and 0.105 according to Goldmeer.

$$
\begin{gathered}
q_{0}=\frac{L H V}{(1+A F R) \gamma R_{g} T_{\text {in }}} \\
H R=1+q_{0}(\gamma-1)(1-p f)
\end{gathered}
$$

$$
P R=H R^{\left({ }^{C \gamma} / \gamma-1\right)}
$$

The purge fraction pf will not be used in this analysis and is set zero throughout this paper. However, this could represent a handle for off-design operation.

A different model is defined by Nalim in (Nalim, 2002). Outlet temperature $T_{\text {out }}$ and isochoric combustion temperature $T_{B}$ are calculated from the energy balance around the combustor (see eq. 4). From this temperature the isochoric pressure $p_{B}$ is found using an isochoric change of state (eq. 5). The isochoric combustion is then followed by isentropic expansion to the outlet condition. The outlet pressure $p_{\text {out }}$ is calculated using the outlet temperature $T_{\text {out }}$ and the isentropic relation in eq. 6 . Both models are compared among others in Figures 1 and 2 in terms of PR over TR (Temperature ratio).

$$
\begin{gathered}
Q=\dot{m} c_{v}\left(T_{B}-T_{\text {in }}\right)=\dot{m} c_{p}\left(T_{\text {out }}-T_{\text {in }}\right) \\
\frac{T_{B}}{T_{\text {in }}}=\frac{p_{B}}{p_{\text {in }}} \\
\frac{p_{\text {out }}}{p_{B}}=\left(\frac{T_{\text {out }}}{T_{B}}\right)^{\frac{\gamma}{\gamma-1}}
\end{gathered}
$$

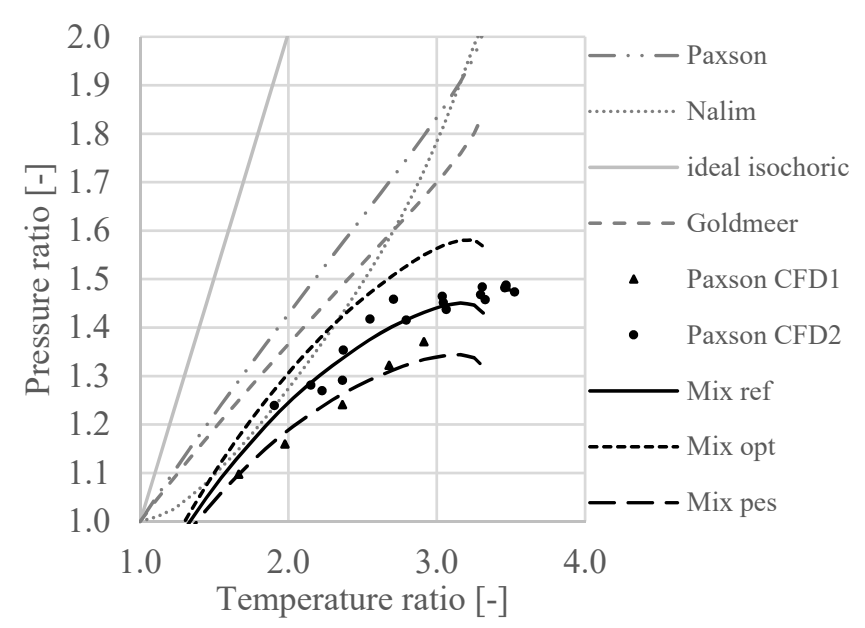

Figure 1: Performance of combustor models at hot inlet condition

Paxson presented in a different work (Paxson, 2010) other combustor models suitable for gas turbine performance studies and compared them with CFD simulations. The results of the CFD simulations are also plotted in Figures 1 and 2 and serve as benchmarks in this paper. The complete setup of the experimentally validated, one-dimensional, time-accurate, reactive, computational fluid-dynamics Euler solver is presented in (Paxson, 1996). Two different CFD data sets are available. The difference is associated to the fuel distribution within the combustion tube. For the data denoted Paxson CFD1 the tube is completely filled with air fuel mixture, whereas an air buffer is present at the tube outlet in the data set Paxson CFD2. The presented combustor models by Goldmeer, Paxson and Nalim are not in good agreement with the CFD data regarding pressure ratio as depicted in Figures 1 and 2 . In both graphs, combustor pressure ratio is plotted against combustor temperature ratio. The first uses inlet conditions of $24 \mathrm{~atm}$ and $792 \mathrm{~K}$ which are identical to the inlet conditions of the CFD simulations. The second plot shows the 
same models at inlet condition of $14 \mathrm{~atm}$ and $677 \mathrm{~K}$. The CFD data points are unchanged for both plots, since only values at higher inlet condition are available. Lines labelled Mix will be introduced later. Generally, at cold inlet condition less fuel is necessary to achieve the same TR compared to hot inlet conditions. Paxson's and Goldmeer's models result in a lower non-dimensional heat addition parameter at cold inlet condition. Consequently, HR and PR are also lower. The difference between hot and cold inlet condition is almost negligible for Nalim's model. The small difference is associated with the combustion temperature ratio of $T_{\text {out }} / T_{b}$.

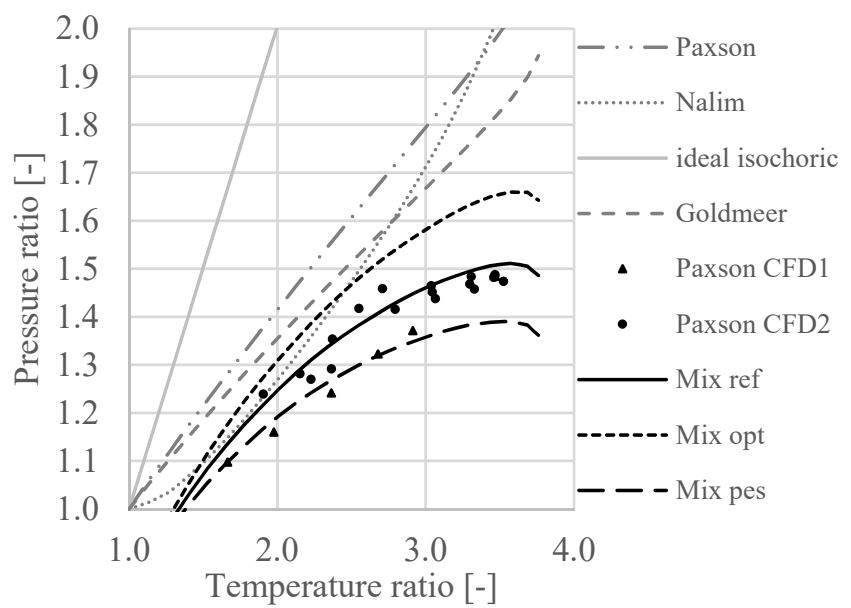

Figure 2: Performance of combustor models at cold inlet condition

\section{Developed model}

For this gas turbine cycle analysis, a model having a closer agreement with Paxson's CFD data is desired. The setup of such a model named "Mix" will be presented in the following section.

In reality, PGC can be achieved by various devices. This paper focuses on pulse detonation combustion, because it eases the introduction of the model. A typical pulse detonation tube can be split into two combustion regimes. First, some sort of ignition source initiates a subsonic deflagration. The flame front encounters blockage bodies to eventually form a detonation, which consumes the remaining fuel towards to combustor tube outlet. The first part of the combustion can be modelled as isobaric combustion with some pressure losses, the second can be modelled as isochoric combustion. Depending on the deflagration to detonation length (DDT), the whole process is more isobaric or isochoric. This idea is implemented in the combustor model.

The combustor outlet temperatures are calculated from the energy balance around the combustor using data tables as for the other models. The gas turbine performance code GTlab-Performance uses combustion tables computed from Cantera. Secondly, a portion of the fuel denoted $r$ is attributed to isobaric combustion $\mathrm{q}_{\mathrm{cp}}$. Again, combustion tables give the temperature rise till $\mathrm{T}_{\mathrm{cp}}$ for this isobaric combustion (eq. 7). This represents the temperature at the end of deflagration.

$$
q_{c p}=F A R \cdot r=c_{p}\left(T_{c p}-T_{i n}\right)
$$

A pressure loss $d P_{\text {Loss }}$ accounts for losses due to friction and heat addition as in eq. 8 .

$$
p_{c p}=p_{\text {in }} \cdot d P_{\text {Loss }}
$$

Finally, outlet pressure is calculated using eq. 9 and assuming an isochoric change of state.

$$
p_{\text {out }}=T_{\text {out }} / T_{c p} \cdot p_{c p}
$$

The model parameter $r$ and the pressure loss were selected to agree with the CFD data by Paxson. A value of $r=0.3$ and a $\mathrm{dP}_{\text {Loss }}=0.8$ match well with the data at the same inlet temperature of $792 \mathrm{~K}$ and $24 \mathrm{~atm}$ as depicted in Figure 1. However, the model deviates at higher TR from the data. Here, stoichiometric combustion temperature limits at $2500 \mathrm{~K}$ are reached leading to lower combustion temperatures. Indeed, the deviation in excess of TR equal 3 is negligible, because they were not encountered throughout this study. The mix model shows a better performance in terms of PR at cold inlet condition because of the constant relative pressure loss. Thus, the absolute pressure loss is smaller and PR higher.

\section{Model variations}

In order to assess the sensitivity of the gas turbine design with respect to different PGC implementations, an optimistic and pessimistic version of the developed model with regards to combustor performance will be created. For the optimistic model (Mix opt) $r=0.24$ is selected and for the pessimistic (Mix pes) $r=0.36$. This means, that there is $20 \%$ more isochoric combustion for the optimistic case and in the pessimistic case there is $20 \%$ more isobaric combustion. The pressure loss is kept constant. A change is not investigated as the effect is expected to be identical in PGC and conventional cycles. The effect on PR is also depicted in Figures 1 and 2.

From Figures 1 and 2 the following conclusions can be drawn:

a) Paxson's, Nalim's and Goldmeer's models perform quite similar. Nalim's model gives a lower PRs at TRs below 2.7. Paxson's model gives the highest PRs.

b) Compared to CFD data, these models over predict combustor performance in terms of PR.

c) At TR below 1.7 the developed model should not be used because it under predicts PR.

d) Pessimistic and optimistic model variations border the region of CFD data points, whereas the reference model captures the trend of the CFD data.

e) Ideal isochoric combustion is far over predicting the combustor performance. That is especially true for high TR.

\section{Thermodynamic analysis}

The combustor model performance within a thermodynamic cycle is presented next. It aims at demonstrating the basic effect of the different PGC models on gas turbine thermal efficiency. The compressor pressure ratio is varied at a turbine inlet temperature of $1400 \mathrm{~K}$. Results for a turbine inlet temperature of $1500 \mathrm{~K}$ are also depicted for the 
developed model. A simple gas turbine model is selected which consists of compressor, combustor and turbine, in order to work out the thermodynamic behaviour. The results are depicted in Figure 3. As for real Brayton cycles, the thermal efficiency rises with pressure ratio and decreases beyond a maximum. An increase in TET rises thermal efficiency and shifts the point of maximum efficiency towards higher pressure ratios. PGC moves the point of maximum thermal efficiency to lower compressor ratios. Nalim's model and the developed model give similar efficiencies at higher pressure ratios. This is because TRs across the combustor are around 2 which give according to Figures 1 and 2 similar PRs. In Figure 3 , at lower compressor pressure ratios, TRs were close to 3.8 . Consequently, published models lead to higher efficiencies because of the elevated PR across the combustor.

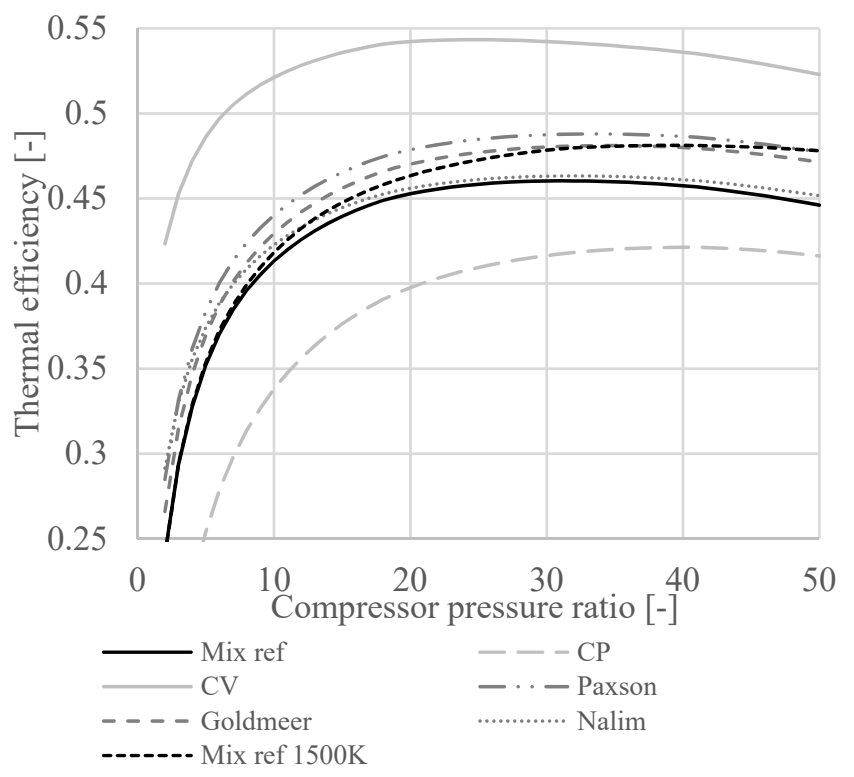

Figure 3: Thermodynamic analysis for varying compressor pressure ratios

\section{OPTIMISATION}

Thermodynamic analyses compare different combustor models usually at constant TET (Figure 3 ) or constant heat input. In reality however, not the TET as such but the resulting blade metal temperature is limiting. Of course, the metal temperature highly depends on TET, but there is also the possibility to improve blade cooling. Increased cooling can be achieved by a rise in cooling mass flow or reduced cooling air temperature, which will have other effects on the gas turbine cycle. Therefore, system-level optimisations are conducted with an in-house software called IPSM (Interface for secondary air system and performance modelling, (Woelki \& Peitsch, 2015)) to represent a realistic case study for the assessment of PGC in gas turbines.

\section{Gas turbine model}

A stationary single spool gas turbine equipped with current state of the art components serves for this demonstration. Constant key performance properties for the design studies are summarised in Table 1 and the modular setup is depicted in Figure 4.
Table 1: Gas turbine design parameter

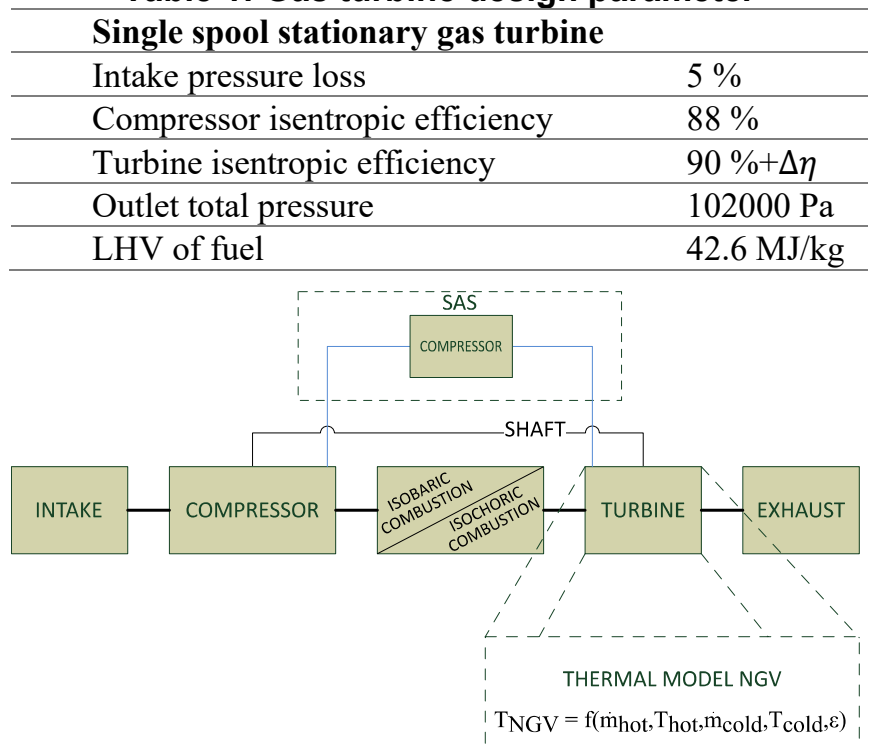

Figure 4: Schematic view of the gas turbine model

Additionally, to the gas turbine comprising intake, compressor, combustor, turbine and exhaust, a SAS and a blade cooling model are connected. The SAS contains a single flow from the compressor outlet to the turbine. Here, the assumption is that $30 \%$ of secondary air is added in the NGV and contributes to blade cooling. The rest is added further downstream. The SAS setup includes a compressor to rise the cooling air's pressure $5 \%$ above turbine inlet pressure, in order to overcome the additional pressure rise in the combustor. This ensures a pressure ratio inside the blades for cooling which is similar to gas turbines with conventional combustors. The additional compression increases the cooling air temperature which is considered in the blade temperature model for the NGV. The thermal model originates from (Louis, et al., 1983). The blade temperature is calculated as a function of hot gas flow and coolant flow properties and a tuning factor $\mathrm{c}$

$$
\frac{\dot{m}_{\text {cold }}}{\dot{m}_{\text {hot }}}=c \cdot \frac{T_{\text {hot }}-T_{m a t}}{T_{m a t}-T_{\text {cold }}}
$$

which was set to 0.098 throughout this study and derived from a study using $10 \%$ cooling air.

These optimisations allow an increase in cooling air, in order to allow higher turbine entry temperatures. However, higher cooling mass flows increase the SAS compressor power which is subtracted from output power and cause higher mixing losses within the turbine. Consequently, higher cooling mass flows will also lower turbine isentropic efficiency. This is captured by a simple literature-based exchange rate (Becker, 2001) as defined in equation (11).

$$
\Delta \eta=20 \cdot\left(0.1-\frac{\dot{m}_{\text {cold }}}{\dot{m}_{0}}\right)
$$

Above $10 \%$ of cooling air, every additional percentage point (PP) results in 0.2 PP lower turbine isentropic efficiency. Contrarily, the efficiency is increased by $0.2 \mathrm{PP}$ for every percentage point of cooling air less than $10 \%$. No distinction is made between film cooling and convective cooling. 


\section{Optimisation setup}

The optimisations aim at representing the first stage of a gas turbine design procedure. The customer has declared a shaft power requirement and investment volume. The latter may result in some form of technology level and might be broken down to an acceptable NGV metal temperature. A conservative metal temperature of $1100 \mathrm{~K}$ was selected based on data provided by (Cerri, et al., 2014). Additionally, the secondary air is limited to a maximum of $35 \%$ of the engine inlet mass flow. The three constraints are listed in Table 2.

Table 2: Constraints

\begin{tabular}{ll}
\hline Output power & $=6.63 \mathrm{MW}$ \\
\hline Turbine NGV blade temperature & $\leq 1100 \mathrm{~K}$ \\
\hline Cooling mass flow / engine mass flow & $\leq 35 \%$ \\
\hline
\end{tabular}

For this optimisation, the two variables are engine mass flow and compressor pressure ratio. The parameter spaces are [2; $50] \mathrm{kg} / \mathrm{s}$ for engine mass flow and $[2 ; 50]$ for compressor pressure ratio. Engine mass flow as a variable was selected because it represents engine size. Furthermore, engine mass flow directly gives information on specific power, because the power output is held constant. Compressor pressure ratio is selected as the main thermodynamic parameter of influence. Since NGV metal temperature and power output were selected as constraints, this setup calculates TETs which deliver the required power output and does not exceed any blade temperature margin. The objective function of the optimisation is thermal efficiency, defined as follows:

$$
\eta_{\text {th }}=\frac{\text { PWoutput }}{\dot{m}_{\text {fuel }} L H V}
$$

The workflow applied for the optimisations is sketched in Figure 5. It includes the optimisation loop providing the degrees of freedom to the gas turbine performance model in order to maximise the thermal efficiency $\eta_{\text {th }}$ and an embedded iterative process. The latter ensures the coolant flow to match the defined metal temperature. The required cooling flow is calculated using eq. 10. Input parameters are directly taken from the performance simulation results. The calculated mass

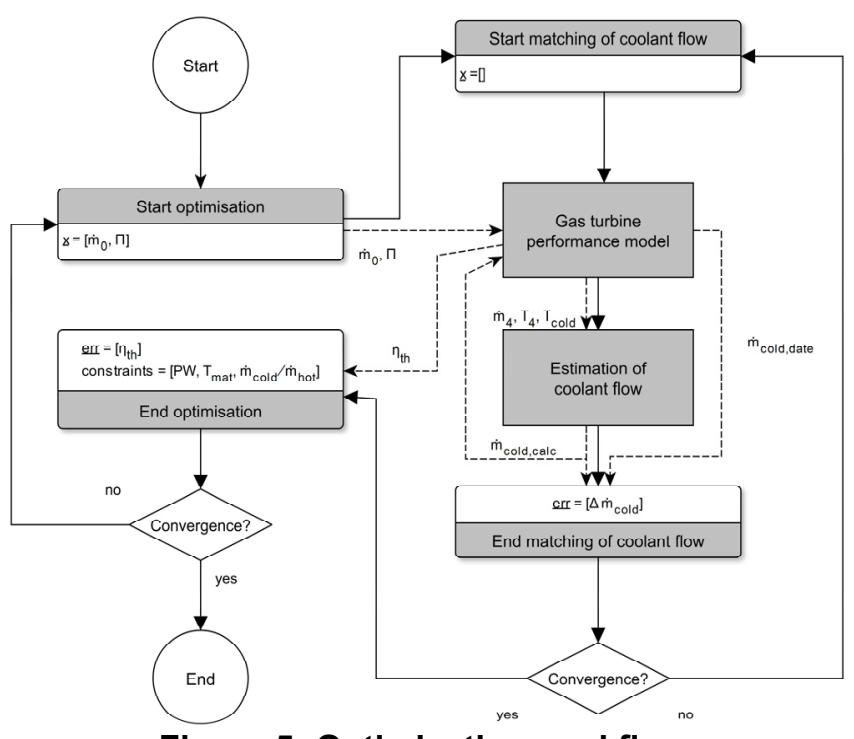

Figure 5: Optimisation workflow flow is used as a new input to the performance model. This loop is iterated till convergence is reached. The optimisation combines two different types of algorithms sequentially. First, an in-house developed evolutionary algorithm is applied to the optimisation problem in order to browse the parameter space for promising regions. Subsequently, a gradient based algorithm continues the optimisation on a set of the best solutions found by the evolutionary algorithm.

\section{RESULTS AND DISCUSSION}

First, thermal efficiency will be plotted within the parameter space for gas turbines with conventional isobaric combustion, ideal isochoric combustion and the reference version of the developed model (Mix ref). Here, main features will be analysed. Second, a back-to-back comparison of all analysed combustor models and their effect on the engine specification for optimal thermal efficiency will be given.

\section{Thermal efficiency within the parameter space}

In the following plots thermal efficiency is plotted over engine mass flow (abscissa) and compressor pressure ratio (ordinate) for the whole parameter space. In total, more than 2000 different engine configurations were evaluated during the sequential optimisation for each combustor model. The following three remarks are valid for all combustor models:

a) No results were obtained at high pressure ratios and low engine mass flows, because the necessary cooling flow to keep the NGV metal temperature below $1100 \mathrm{~K}$ was in excess of $35 \%$ of the engine mass flow.

b) The space at low engine mass flows remained blank, because the required power output could not be obtained with engine mass flow.

c) At high engine mass flows and low pressure ratios, no cooling air is required since the TET is below the maximum NGV metal temperature.

d) The colormaps are tailor-made for each plot. No direct comparison is possible. That has been accepted in order to better represent efficiency changes close to optimum.

Comparing real engine efficiencies in Figure 6 with results from simplified thermodynamic analysis in Figure 3, maximum efficiency and location of optimum efficiency deviate substantially. The thermal efficiency is lower and optimum efficiency occurs at lower pressure ratios in Figures 6-8. This is surprising since TET is roughly $200 \mathrm{~K}$ higher in the real engine cycle as in the thermodynamic analyses. Usually, higher TET move optimum cycle pressure ratio to higher values. Apparently, the consideration of SAS and blade cooling shifts this to lower pressure ratios. Furthermore, the blank space to the left is large, leading to the conclusion that the specific power is small. In contrast, the blank space to the top is small compared to the following results for ideal isochoric combustion and the developed model. This shows that blade metal temperature and secondary air mass flow constraints are less limiting. 
Looking at results for isochoric combustion in Figure 7, these constraints are reached at lower pressure ratios. This is because PGC cooling air is further compressed, thus driving up its temperature. Higher cooling air temperature increases NGV metal temperature. The maximum thermal efficiency is encountered at lower compressor ratios. This is straight forward since combustion further rises the cycle pressure. Therefore, compressor pressure ratio is decreased. Interestingly, the engine mass flow is almost identical for both setups. Apparently, specific work is not affected by PGC. In general, maximum efficiency could be increased by $13 \mathrm{PP}$ compared to isobaric combustion. This explains the high interest in PGC technologies. Unfortunately, this case represents only the ideal form of isochoric combustion and is too optimistic as shown in Figure 1 and 2. A more realistic case will be investigated in Figure 8 .

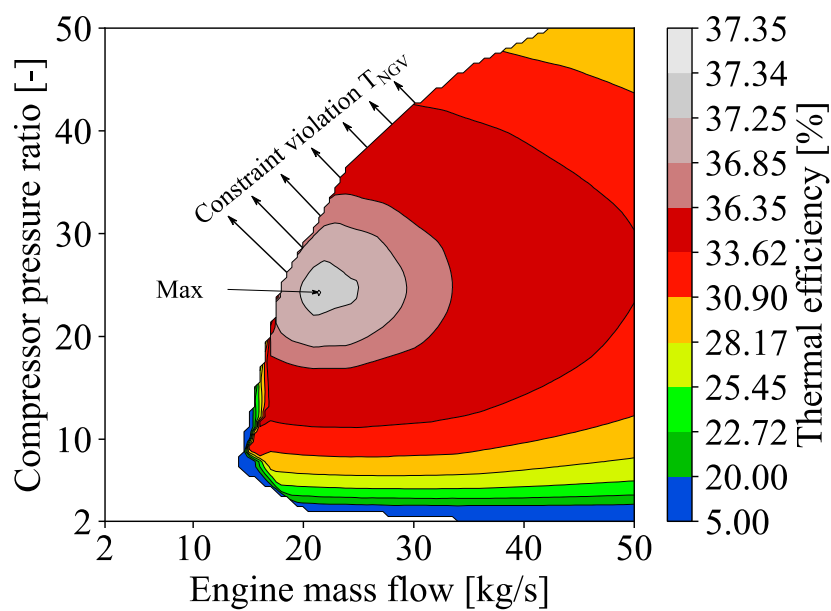

Figure 6: Optimisation results for isobaric combustion

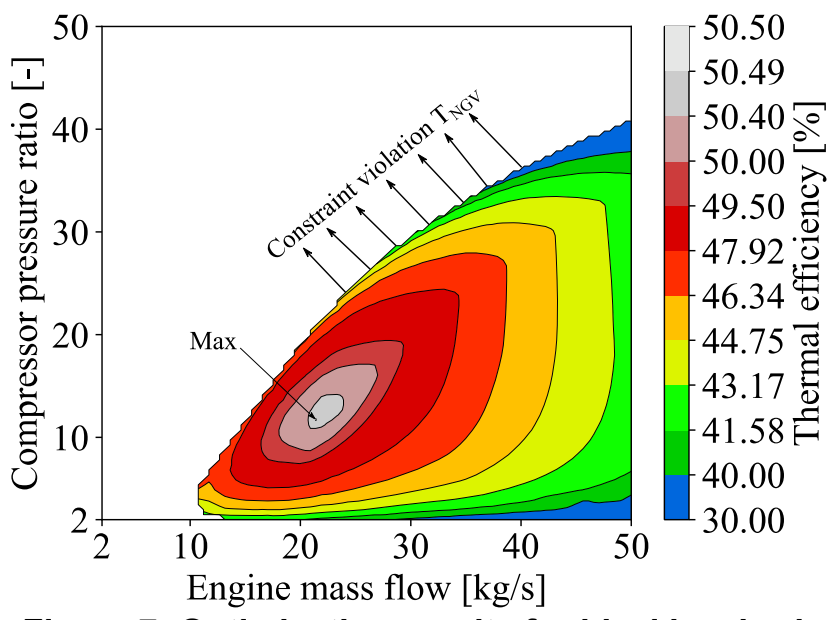

Figure 7: Optimisation results for ideal isochoric combustion

In Figure 8, the developed model with reference settings is used. The thermal efficiency gain is still $5 \mathrm{PP}$ compared to isobaric combustion. As already seen in Figure 3, the developed model represents a change of state somewhere between isobaric and isochoric. This is still true after the optimisation since compressor pressure ratio for maximum thermal efficiency is in between pure isobaric combustion and ideal isochoric combustion. Again, the engine mass flow is not altered.

Looking at the model sensitivities, the upper 4 PP in thermal efficiency are encountered roughly from light grey to light red. This area encompasses a main portion of the parameter space for isobaric combustion and less space for isochoric combustion. From this it can be concluded that thermal efficiency is less sensitive for isobaric combustion. For this type of cycle, the design space is broad in which relatively higher efficiencies are achievable. The parameter space is narrower for PGC.

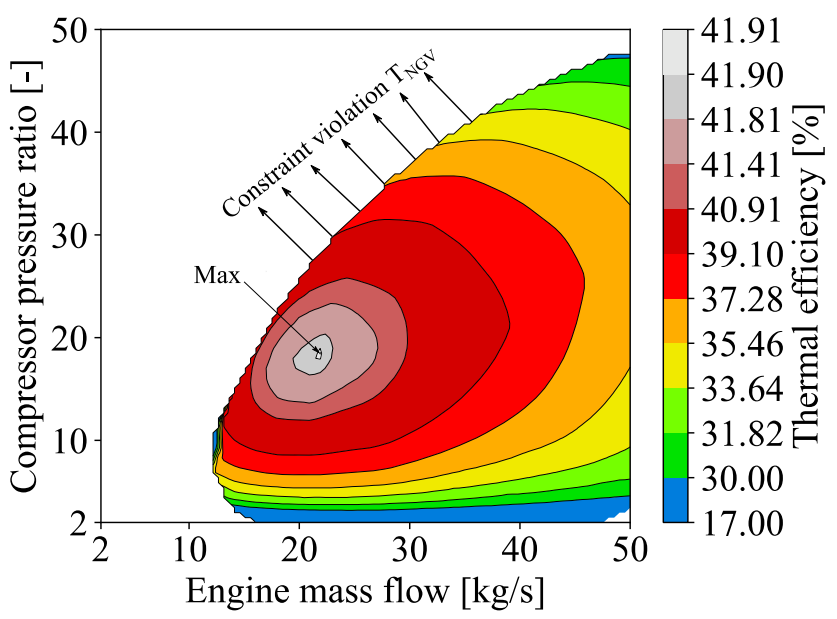

Figure 8: Optimisation results for Mix ref combustor model

\section{Optimal engine specification}

The optimisations lead to gas turbine specification for maximum thermal efficiency for each combustor model. Now, the resulting specification will be compared based on selected parameters. The gas turbine with conventional isobaric combustion serves as a reference case and the relative changes to this reference are given in percentage. Table 3 summarises the absolute values for this reference case.

Table 3: Summary isobaric combustor

\begin{tabular}{ll}
\hline Thermal efficiency & $37.34 \%$ \\
\hline Engine mass flow & $21.35 \mathrm{~kg} / \mathrm{s}$ \\
\hline Compressor pressure ratio & 24.03 \\
\hline TET & $1603.14 \mathrm{~K}$ \\
\hline
\end{tabular}

The first set of specifications comprises thermal efficiency, engine mass flow, compressor pressure ratio and TET. Since the combustor model of Paxson and Goldmeer are similar, only the original model of Paxson is shown.

Figure 9 depicts the effects of PGC on the gas turbine design. The following conclusions are true for all analysed combustor models. Not only does PGC increase thermal efficiency, it also reduces compressor pressure ratio and lowers TET. For ideal isochoric, conventional isobaric and the developed models the engine mass flow remains constant for maximum thermal efficiency. However, using Paxson's model the mass flow for maximum thermal efficiency increases and for Nalim's model decreases. This can be explained by looking at the TET. Here, Paxson's model results in a large TET reduction, which in 
return lower the cycle's specific power. Consequently, engine mass flow is increased in order to match the power output. Nalim's model leads to a TET reduction of only $4 \%$ compared to isobaric combustion. Hence, the specific power is higher, lowering necessary engine mass flow to meet the target of 6.63 MW. However, thermal efficiency is only marginally reduced moving away from the point of highest thermal efficiency. This can be seen in Figures 6-8. A change of $\pm 3 \mathrm{~kg} / \mathrm{s}$ in mass flow alters thermal efficiency by only $0.1 \mathrm{PP}$.

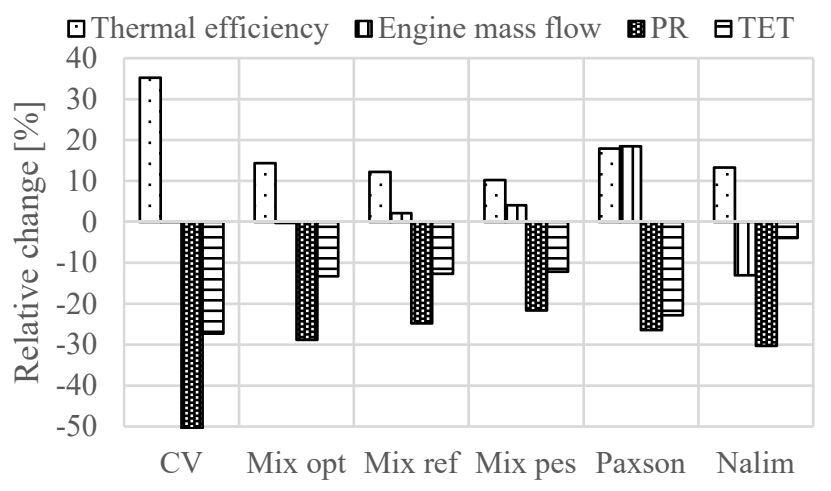

Figure 9: Comparison of global engine specification

Figure 10 focuses more on the combustion and consequences for the SAS. TRs and PRs across the combustor are plotted using the right axis and the percentage of secondary mass flow referred to engine mass flow and SAS compressor power referred to engine output power are plotted using the left axis.

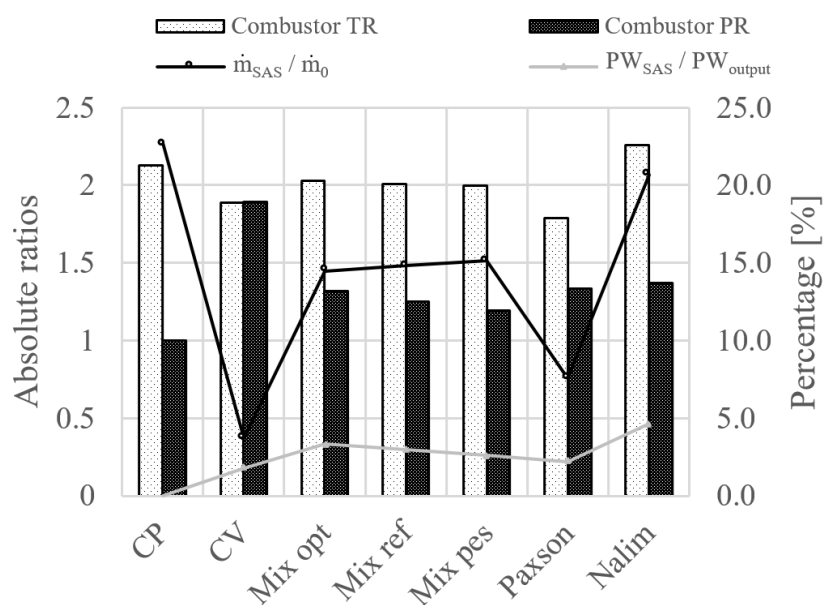

Figure 10: Results combustor model and SAS

The optimisations result in TRs across the combustor close to 2. Here CFD data is available (see Figure 1 and 2). The combustor behaviour is therefore valid, and no extrapolation occurred. Furthermore, investigated combustor inlet conditions are close to the inlet conditions Paxson used for the CFD simulations. This stresses, again, the validity of the results. The SAS mass flows are reduced for PGC. This is a direct result of lower TETs. However, the additional compressor of the SAS consumes up to $5 \%$ of the power output, which is a direct penalty for thermal efficiency. Regarding the product of compressor and combustor pressure ratios, turbine inlet pressures are almost identical for the different setups.

\section{Sensitivity study for optimistic and pessimistic model}

The ratio of isobaric to isochoric combustion was changed for the optimistic and pessimistic model by $\pm 20 \%$. This can be interpreted as a short and longer DDT length. The effect on main engine parameters is given in Figure 10.

Interestingly, there is almost no effect on TET. Contrarily, the power requirement of the SAS compressor is most affected and rises with isochoric combustion. Thermal efficiency is changed by almost $\pm 2 \%$.

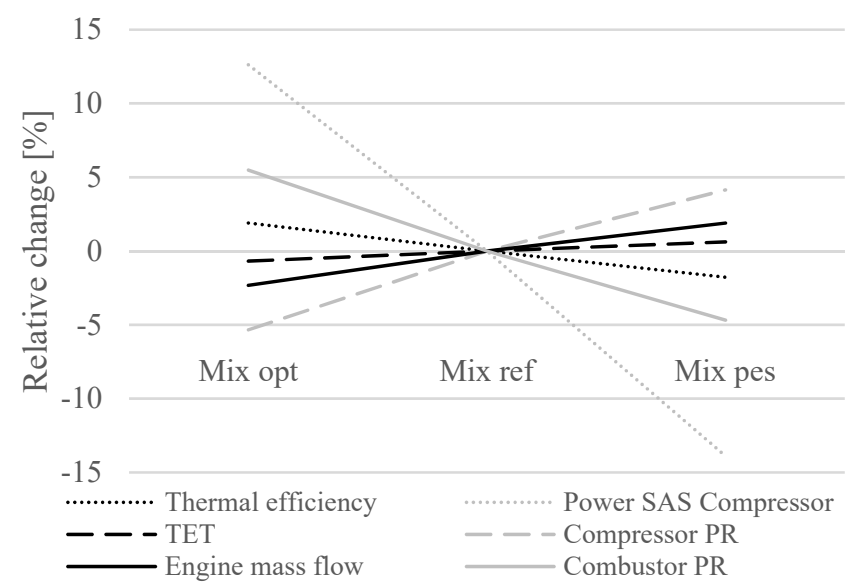

Figure 11: Sensitivity study

\section{CONCLUSION}

An extensive literature survey on PGC models suitable for $0 \mathrm{D}$ gas turbine performance simulation has been conducted. Three published PGC models were compared to published CFD data und showed minor agreement. Therefore, a new algebraic model has been developed, which is in closer agreement with the CFD data. In order to account for uncertainty, models for less and more fractional isochoric combustion were added. A stationary gas turbine in the low power class segment has been modelled in GTlabPerformance and serves as a vehicle for the analysis of the different PGC models. The gas turbine comprises the secondary air system including an additional compressor, a blade metal temperature model and a penalty for increased cooling air. This gas turbine was optimised regarding thermal efficiency under the consideration of three side constraints for each combustor model. The following conclusion can be drawn:

- Real engine optimum configuration does not agree with theoretical thermodynamic evaluations (Fig. 3 and 6-8).

- Realistic PGC increases thermal efficiency of up to 5 PP while reducing compressor pressure ratio and TET.

- Temperature ratios across the combustor are in the order of 2 and pressure ratios are between 1.37 (Model Paxson) and 1.19 (Model Mix pes).

- Thermal efficiency is more sensible to gas turbine design changes for PGC than for isobaric combustion. 
- SAS compressor power may amount to $5 \%$ of the overall power output.

- The sensitivity study showed the effect of reduced DDT length. $20 \%$ more fuel is burnt at constant volume condition which ultimately improves thermal efficiency by $2 \%$.

Future work will consider the effect of different NGV metal temperatures on cycle design and assess the potential of intercooling and recuperation in conjunction with PGC.

\section{NOMENCLATURE}

Symbols

$\begin{array}{ll}\text { AFR } & \text { Air to fuel ratio } \\ \mathrm{C} & \text { Model parameter } \\ \mathrm{c} & \text { Cooling coefficient } \\ \mathrm{cp} & \text { Heat capacity at constant pressure } \\ \mathrm{cV} & \text { Heat capacity at constant volume } \\ \mathrm{dPLoss} & \text { Pressure loss } \\ \dot{\mathrm{m}} & \text { Mass flow } \\ \mathrm{p} & \text { Pressure } \\ \mathrm{pf} & \text { Purge fraction } \\ \mathrm{PW} & \text { Shaft power / output power } \\ \mathrm{q} & \text { Specific heat } \\ \mathrm{Q} & \text { Heat } \\ \mathrm{r} & \text { Model parameter } \\ \mathrm{R}_{\mathrm{g}} & \text { Specific gas constant } \\ \mathrm{T} & \text { Temperature } \\ \gamma & \text { Ratio of specific heats } \\ \eta_{\text {th }} & \text { Thermal efficiency } \\ \text { Indices } & \\ 0 & \text { Reference, engine inlet } \\ \mathrm{B} & \text { Station downstream isochoric combustion } \\ \text { cold } & \text { Cooling air } \\ \mathrm{cp} & \text { Station downstream isobaric combustion } \\ \text { hot } & \text { Annulus air } \\ \text { in } & \text { Inlet } \\ \text { out } & \text { Outlet } \\ \mathrm{Abb} & \end{array}$

Abbreviations

CFD Computational fluid dynamics

$\mathrm{CP} \quad$ Constant pressure combustion

CV Constant volume combustion

DDT Deflagration to detonation length

FJ Fickett Jacobs

GTlab Gas turbine laboratory

HR Enthalpy ratio

IPSM Interface for performance and secondary air system modelling

LHV Lower fuel heating value

NGV Nozzle guide vane

PGC Pressure gain combustion / pressure gain combustor

PP Percentage point

PR Pressure ratio

SAS Secondary air system

TET Turbine entry temperature

TR Temperature ratio

ZND Zeldovich von Neumann Döring

\section{ACKNOWLEDGMENTS}

The authors gratefully acknowledge the support by the Deutsche Forschungsgemeinschaft (DFG, German Research Foundation) as part of the Collaborative Research Centre CRC 1029 ,Substantial efficiency increase in gas turbines through direct use of coupled unsteady combustion and flow dynamics“ in project D01.

Additionally, we thank the German Aerospace Centre as chair's partner providing the performance code GTlabPerformance.

\section{REFERENCE}

Becker R. (2001). Auslegung und deterministische Optimierung stark gekühlter Turbinen. $\mathrm{PhD}$ thesis, TU München

Becker R. G., Wolters F., Nauroz M. and Otten T., (2011). Development of a gas turbine performance code and its application to preliminary engine design. Deutscher Luft-und Raumfahrt Kongress (DLRK 2011), Bremen, Germany. S. $27-$ 29.

Cerri G., Chennaoui L., Giovannelli A. and Mazzoni S., (2014). Expander models for a generic $300 \mathrm{MW}$ f class gas turbine for igcc. In ASME Turbo Expo 2014: Turbine Technical Conference and Exposition

Endo T., Kasahara J., Matsuo A., Inaba K., Sato S. and Fujiwara T. (2004). Pressure history at the thrust wall of a simplified pulse detonation engine. AIAA journal, Volume 42, pp. 1921-1930.

Goldmeer J., Tangirala V. and Dean, A., (2008). System-level performance estimation of a pulse detonation based hybrid engine. Journal of Engineering for Gas Turbines and Power, Volume 130, p. 011201.

Grönstedt T. et al., (2014). First and second law analysis of future aircraft engines. Journal of Engineering for Gas Turbines and Power, Volume 136, p. 031202.

Heiser W. H. and Pratt D. T., (2002). Thermodynamic cycle analysis of pulse detonation engines. Journal of Propulsion and Power, Volume 18, pp. 68-76.

Kaemming T. A. and Paxson D. E., (2018). Determining the Pressure Gain of Pressure Gain Combustion. AIAA Propulsion and Energy Forum, 9-11 July.

Louis J. F., Hiraoka K. and El Masri, M. A., (1983). A comparative study of the influence of different means of turbine cooling on gas turbine performance. Turbo Expo: Power for Land, Sea, and Air. 10.1115/83-GT-180

Nalim M. R., (2002). Thermodynamic limits of work and pressure gain in combustion and evaporation processes. Journal of Propulsion and Power, Volume 18, pp. 1176-1182. Paxson D. E., (1996). Numerical simulation of dynamic wave rotor performance. Journal of Propulsion and Power, Volume 12, pp. 949-957.

Paxson D. E., (2004). Performance evaluation method for ideal airbreathing pulse detonation engines. Journal of Propulsion and Power, Volume 20, pp. 945-950.

Paxson D. E., (2010). A simplified model for detonation based pressure-gain combustors. $46^{\text {th }}$ AIAA/ASME/SAE/ASSEE Joint Propulsion Conference and Exhibit

Paxson D. E. and Kaemming T., (2014). Influence of unsteadiness on the analysis of pressure gain combustion 
devices. Journal of Propulsion and Power, Volume 30, pp. 377-383.

Paxson D. W., (1992). A General Numerical Model for Wave Rotor Analysis. NASA TM 105740.

Snyder P. H. and Nalim M. R., (2012). Pressure gain combustion application to marine and industrial gas turbines. Turbo Expo: Power for Land, Sea, and Air. 10.1115/GT201269886. pp. 409-422.

Sousa J., Paniagua G. and Morata E. C., (2017). Thermodynamic analysis of a gas turbine engine with a rotating detonation combustor. Applied energy, Volume 195, pp. 247-256.

Stathopoulos P., (2018). Comprehensive Thermodynamic Analysis of the Humphrey Cycle for Gas Turbines with Pressure Gain Combustion. Energies, Volume 11.

Vutthivithayarak R., Braun E. M. and Lu F. K., (2012). On thermodynamic cycles for detonation engines. In: Kontis $\mathrm{K}$. (eds) 28th International Symposium on Shock Waves. Springer, Berlin, Heidelberg. pp. 287-292.

Woelki D., Peitsch D., (2015), Modellierung variabler Sekundärluftsysteme zur Bewertung ihrer Auswirkungen auf das Gesamtsystem Gasturbine. Deutsche Luft- und Raumfahrt Kongress 2015, DLRK340112

Xisto C. et al., (2017). Analytical Model for the Performance Estimation of Pre-Cooled Pulse Detonation Turbofan Engines. Turbo Expo: Power for Land, Sea, and Air. 10.1115/GT201763776 